\title{
Textile recycling- A review
}

\author{
Akram H M Ali 1, *, Elawad F Elfaky, Salah A Mohammed, Hago E Haroon, Isam A Eshag and Elsir Hassan \\ Laboratory of High Performance Fibers \& Products, Department of Textiles Engineering, College of Engineering \& \\ Technology of Industries, Sudan University of Science and Technology, Khartoum, Sudan.
}

Global Journal of Engineering and Technology Advances, 2021, 06(03), 069-074

Publication history: Received on 06 February 2021; revised on 08 March 2021; accepted on 10 March 2021

Article DOI: https://doi.org/10.30574/gjeta.2021.6.3.0015

\begin{abstract}
Textiles are one of the largest growing waste streams in the world and are expected to continue to grow due to more frequent consumption and greater demand from fast fashion, along with this come high consumption of chemicals, energy, and water, which generate significant environmental impacts globally. Textiles in landfill biodegrade to form methane gas which is released into the air and is not suitable for human consumption, is one of the most effects factor that recycling is addressing by diverting textile from landfill. A logical approach to diverting existing textile waste streams is the adoption of textile recycling technologies and systems.
\end{abstract}

Key Words: Textile Recycle; Pollution; Garment Manufacturing; Fiber Waste

\section{Introduction}

The textiles and apparel industry is one of the largest and fastest growing global industrial sectors, owing to increasing population, the rise in consumption, the diverse applications of textiles, and greater productivity in mass production processes. With a 1.3 trillion USD annual revenue in 20161, the global clothing industry is the largest consumer of textiles. 2 Annual production has nearly doubled since 2000, surpassing 100 billion units in 2015 with apparel consumption expected to rise $63 \%$ by 2030 . This increase is partly due to the burgeoning fast fashion industry, which relies on shorter production cycles and style turnaround, often at lower prices, enabling a larger selection and choice for consumers. 3

As a resource and energy intensive industry, the apparel sector's presence is far-reaching with associated environmental, economic, and social impacts across the value chain. Total fiber production in the global textile industry had increased by nearly 20\% to 103 million tons between 2011 and 2017.4 The textile and apparel industry is expected to increase its $\mathrm{CO} 2$ emissions by more than $60 \%$ (roughly 2.5 billion tons per year) by 2030 while also experiencing a $50 \%$ increase in freshwater consumption from 79 million cubic meters in 2017 [1]. The ecological footprint of the industry, specifically the impacts of textile and associated chemical waste, remains as both a continuing global challenge and an opportunity to drive innovative change in processes, products, and sustainable development for the future.

\subsection{Scope and Methodology}

This review explores the recycling technologies for cotton and regenerated cellulose and wool, as they are the most commonly used fibers in garment manufacturing. Emphasis is placed on advancements in fiber-to-fiber recycling technologies. Issues pertaining to current dyeing techniques and possible impacts during recycling are explored, and alternative and emerging innovative techniques are outlined. The following topics are presented:

\footnotetext{
${ }^{*}$ Corresponding author: Akram H M Ali

Laboratory of High Performance Fibers \& Products, Department of Textiles Engineering, College of Engineering \& Technology of Industries, Sudan University of Science and Technology, Khartoum, Sudan.
} 
- Summary of existing textile recycling technologies (mechanical and chemical)

- Identification of existing and emerging textile recycling technologies of prevalent fibers

- Summary of existing dyeing techniques, and chemical classes in use of potential concern used in dyeing and finishing processes

- Identification of alternative and novel coloring techniques, technologies for decolourization, and finishing chemistries adopted commercially and under development

- Identification of key enablers for textile recycling adoption, and greater sustainability in the textiles and apparel industry

The research methodology utilized in the report included a literature review of available industry reports, news sources, and data, technical research in the field, as well as qualitative methods through interviews with technology providers and researchers. Owing to both the proprietary nature and limited data available on some of concepts explored, there are still several gaps identified from the topics presented. This work is intended to serve as an informative piece to present the existing knowledge base of textile recycling technologies, coloring and finishing methods

\section{Background}

Global demand for textile materials is expected to continue to rise due to population growth, improvement of living standards, rapidly changing fashion trends as a result of increased style turnaround and shortened garment life cycles, coupled with lower prices [2,3]. With this comes the generation of textile and associated chemical waste streams. While still comprising a small proportion of total global waste streams (total of 1.9 billion tons annually3), textile waste is one of the most rapidly growing waste streams. This is due to low rates of utilization and recycling, resulting in high throughput levels; with approximately 83.5 million tons of waste produced annually (2015), and expected to increase by $62 \%$ by $2030[4,5]$. From the lifecycle standpoint, the apparel industry is considered as one of the most polluting due to the high volume of resources used, resulting in ecological impacts. $[3,5,10]$. In recent times, there have been emerging concerns regarding microplastics release into marine environments, with the majority of suspected microplastics comprising synthetic fibers, which enter potable water systems, or are captured in municipal wastewater treatment plants $[6,7]$. It has been estimated that $34.8 \%$ of primary microplastics release into world oceans are derived from the laundering of synthetic textiles [8].

Textile Waste was estimated that the total global apparel waste (83.5 million tons in 2015) was greater than $90 \%$ of total global fiber production (94.5 million tons in 2016) $[5,9,10]$.

Textile waste streams comprise pre-consumer (or post-industrial) waste, and post-consumer waste. Pre-consumer waste includes materials arising from industrial and commercial processing of textiles or manufacturing of garments (scraps, excess inventory, damaged or defective materials, samples). Post-consumer waste includes end-use of products, such as recalled inventory, items returned or disposed of by the consumer

\subsection{Textile Fibers}

Global fiber production in 2016 was estimated to be 94.5 million tons, dominated by synthetic fibers (68.3\%) predominantly polyester (64\%) estimated at 64.8 million tons, followed by cotton (22\%), man-made cellulosic (6\%), and animal-based fibers (1.5\%- 80\% wool, 20\% down) Figure (1).18 Synthetic fibers comprise production from organic compounds derived from non-renewable sources (petroleum), and inorganic-based materials (ceramics and glass). Natural fibers are derived from plants (cellulosic), animal proteins (wool, silk), or minerals (asbestos) [9]. 
Synthetics, $68.3 \%$
(64\% polyester, $36 \%$ other)

Cotton, $22 \%$

Man-made Cellulosics, 6\%

Animal based, $1.5 \%$

(80\% wool, $20 \%$ down)

Others, $2.2 \%$

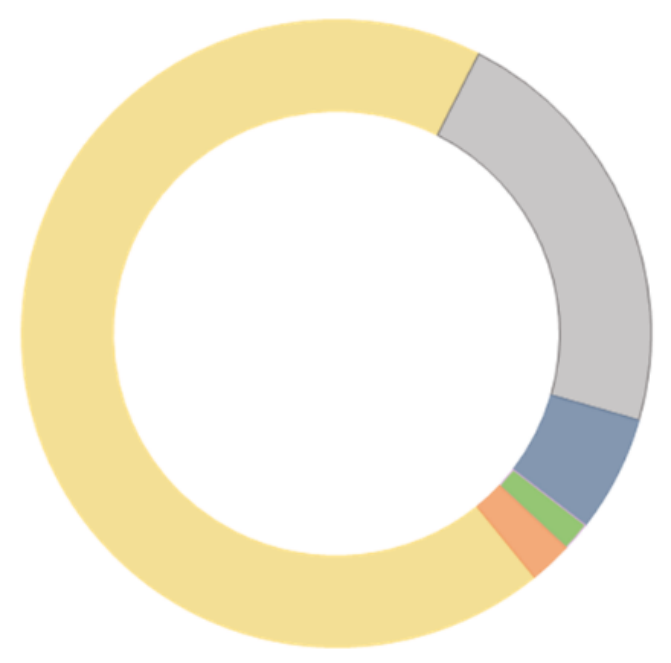

Figure 1 Global fiber production in 2016. [10].

\section{Cotton}

Cotton is the most widely produced natural textile fiber, owing to its strength, lightweight, and absorbency. The staple fibers grow around the cotton seed (as seed hairs), and range from 22 to $32 \mathrm{~mm}$ in length, with longer fibers having higher quality. Cotton fibers contain $88-97 \%$ cellulose, with the remaining constituents which include waxes, proteins, and pectinic substances. 80 Chemicals and water usage from both crop and textile production are associated with significant environmental pollution and impacts.

Conventional cotton production from its cultivation to harvesting, requires the use of arable land, large amounts of water, and agrochemical resources (i.e. pesticides and fertilizers) There have been efforts towards more sustainable agricultural processes, which includes the transition to low-input organic management system cotton farms, that include sustainable practices which enable water and energy reduction, and sophisticated fertilizer usage. Other combined efforts through partnerships with organizations including Better Cotton Initiative and Textile Exchange also forms part of the Preferred Cotton Fiber Production Segment in the apparel industry.

The textile production process from cotton fibers to fabrics for garments requires the extensive use of chemicals and energy to reduce the level of natural impurities found in the fiber, improve dye and finishing chemical uptake, and impart functional properties to the final fabric (i.e. high absorbency and hydrophilic properties) [12,13].

Recycling provides alternatives to both the diversion of waste from landfill, and raw material production utilizing agricultural land. The mechanical recycling of cotton from is well established and is applied to both pre- and postconsumer waste, an generally entails the respinning of recycled combined with virgin material, without additional chemicals. 3 The majority of chemical recycling processes of cotton is in developmental stage, or close to commercial adoption, and include either dissolution processes to recover the cellulosic fibers, or depolymerization processes to generate other by-products, namely regenerated man-made cellulosic.

The overall ecological advantages of recycled cotton fibers include, lower water and energy requirements (20\% lower), fewer chemicals, and lower emissions generation and natural resource consumption owing to the elimination of farming operations associated with conventional cotton production [14].

\subsection{Technology used for recycling of textile waste}

Based on several research projects about textile recycling in Finland the main problems identified have been linked to logistics and economic issues $[15,16]$. Those are also the greatest obstacles to start a successful business in the textilerecycling field. The amount of textile waste is fairly small and distances are long, which necessitate effective logistics. The economic viability is challenging as big investments and specialty machines are required for recycling waste textile to new fibers. Since textile waste is often not considered as particularly harmful and the value is currently not very high this provides rather week incentives for businesses to enter this market. Specialized actors are also needed to sort, handle and deliver the heterogeneous material coming from consumers. All these phases need much manual work. 
Hence, there is neither much business dealing with textile waste in Finland nor any innovative recycling technologies. Chemical recycling is also very little used method in Finland Some social companies are operating in this field, processing manually e.g. industrial cloths, as described before. However, the interest is increasing and so is the demand for reused fibers, thread and yarn. So, there is a potential for better textile waste recycling. In fact, this year in Finland, some positive signals and initiatives for the better management of textile flows and waste recycling have been found on many levels, both in administrative organizations and private trading and recycling companies [2].

\subsection{Mechanical Recycling}

The general process of mechanical recycling of cotton for apparel applications involves the respinning of waste fibers. Given that the mechanical process breaks the fiber, quality and strength are reduced and therefore, the recovered staple fiber must be blended with either virgin cotton fibers or other fibers to impart both increased strength, and to provide color matching, thereby eliminating the need for re-dyeing. Other applications that utilize pre-consumer and postconsumer cotton as feedstock materials include a variety of nonwovens used for insulation, automotive felts, oil sorbent sheeting. The main challenge cited for widespread commercial adoption of closed-loop respinning lies in facilitating logistical support to increase volume of material collected and processed $[17,18]$.

\subsection{Second-Hand Clothing}

The largest volume of goods (roughly 48\%) is sorted for second hand clothing markets, primarily for export to developing countries or disaster relief. One informant reported that "used apparel serves as the largest export from the United States based on volume" (personal communication with informant, May 10, 2004). On many street corners throughout the developing world, racks of Western clothing are being sold [19].

\subsection{Conversion to New Products}

Two categories of conversion to new products were used. Shoddy (from knits) and mungo (from woven garments) are terms for the breakdown of fabric to fiber through cutting, shredding, carding, and other mechanical processes. Then fiber is then re-engineered into value-added products. These value added products include stuffing, automotive components, and carpet under lays, building materials such as insulation and roofing felt, and low-end blankets. The majority of this category consists of unusable garments-garments that are stained, torn, or otherwise unusable. One informant, however, was sorting for $100 \%$ cotton sweaters because he was selling shredded cotton fiber to mix with sand for use in a "Punch-n- Kick" bags made by one of the world's largest sporting manufacture companies. A vast number of products are made from reprocessed fiber because much of this fiber is re-spun into new yarns or manufactured into woven, knitted, or non-woven fabrications including garment linings, household items, furniture upholstery, insulation materials, automobile sound absorption materials, automobile carpeting, and toys (personal communication, Querci, July 22, 2000). New yarn producers like those in Prato, Italy who reduce

cashmere sweaters to fiber, spin new yarns and produce cashmere blankets for the luxury market. This process represents an economic and environmental saving of valuable fiber that would otherwise be lost to the landfill. Ironically, the most unusable and damaged of post-consumer textiles often has the highest level of specifications forced upon it by the end-use industries (e.g., building, auto, aeronautics, and defense). Another informant reports that used fibers are being used in the production of U.S. Currency [20].

\subsection{Wiping and Polishing Cloths 17\%}

Clothing that has seen the end of its useful life as clothing may be turned into a wiping or polishing cloth for industrial use. T-shirts are a primary source for this category because the cotton fiber makes an absorbent rag and polishing cloth. Bags of rags can be purchased at retail stores such as in Wal-Mart's automotive department. But in some cases, because of its excellent wicking and oleophilic properties, some synthetic fiber waste (particularly olefin) is cut into wipers to serve in industries where oily spills need to be cleaned up or wiped. One informant said that he sells wiper rags that he has reclaimed from the sorting process to a washing machine manufacturer for use-testing of the machines. Another informant sells oleophilic wipers to the oil refining industry. And yet another informant reported that oil spills are being cleaned up with large "snakes" that are made with a combination of oleophilic and hydrophobic used fibers.

\section{Conclusion}

The environmental benefits gained from using recycled raw materials rather than virgin materials to make these products include conservation of natural resources as well as reduced energy consumption, carbon dioxide (CO2) and other emissions, and waste going to landfills 
To recycle successfully, consumers must embrace the system, not just make an occasional charitable donation. Meanwhile arbiters must continue to develop new value-markets and market the after-use possibilities so that the system functions at full capacity and with commitment from all.

To reach the goal of a circular economy set by the European Union, end-of-life textiles have to be recycled in such a way that new fiber material with similar properties to the virgin material can be produced. While this is already a technically achievable strategy for sorted textile waste materials consisting of only one type of fiber material, multi-material textiles are a problem for recycling purposes. These multi-material textiles should therefore be avoided and a 'design for recycling' approach should be established in the textile and apparel industry.

In the cases where textiles with multiple different fiber materials are unavoidable, novel recycling concepts have to be developed that can separate the different fiber materials from each other either directly, or through selective processing of individual fiber materials into useful chemicals. Biochemical processes seem to be the most suitable solution for this task because of their high selectivity and ecological operating conditions.

\section{Compliance with ethical standards}

\section{Acknowledgments}

I would like to express my sincere thanks to the work team, for their valuable contribution and great merit of producing the paper in this way

Disclosure of conflict of interest

No Disclosure of conflict of interest

\section{References}

[1] Euromonitor International Apparel \& Footwear, "Global fashion industry statistics - International apparel," Fashion United, 2016. Available: https://fashionunited.com/global-fashion-industry-statistics/

[2] Ellen McArthur Foundation and Circular Fibres Initiative, "A New Textiles Economy: Redesigning Fashion's Future," 2017.

[3] Oakdene Hollins, Apparel and Footwear Recycling Innovation," Sustainable Apparel Coalition, 2014.

[4] K Storry and A McKenzie, "Unravelling the Problem of Apparel Waste in the Greater Vancouver Area," 2018.

[5] A Peterson, "Anna Peterson, PhD Thesis: Towards Recycling of Textile Fibres: Separation and Characterization of Textile Fibers and Blends," Master's Thesis: Chalmers University of Technology, 2014.

[6] J J Lu and H Hamouda, "Current Status of Fiber Waste Recycling and its Future," Advanced Materials Research, 2014; 87, p 122-131.

[7] K Niinimaki and L Hassi, "Emerging design strategies in sustainable production and consumption of textiles and clothing," Journal of Cleaner Production, 2011;19, p 1876-1883.

[8] E A Gies, J L LeNoble, M Noel, A Etemadifar, F Bishay, E R Hall and P S Ross, "Retention of microplastics in a major secondary wastewater treatment plant in Vancouver, Canada," Marine Pollution Bulletin, 2018; 133, p. 553-561.

[9] J Boucher and D Friot, "Primary microplastics in the oceans: A global evaluation of sources p.21," International Union for Conservation of Nature and Natural Resource (IUCN), Gland, 2017.

[10] Tetra Tech EBA Inc., "2016 Waste Composition Monitoring Program," Metro Vancouver, Burnaby, 2016.

[11] Kim., H., \& Damhorst, M. L. Environmental concern and apparel consumption, Clothing and Textiles Research Journal, 1998; 16(3), p. 126-133.

[12] Hamilton, J. A. , The macro-micro interface in the construction of individual fashion forms andmeanings. Clothing and Textiles Research Journal, 1997; 15(3), p. 164-171.

[13] Mayrhofer, W, Social systems theory as theoretical framework for human resource management -benediction or curse? Management Revue. Mering: 2004; 15, 2, 178-14 
[14] Kim Y., Forney E, \& Arnold, E, Environmental messages in fashion advertisements: Impact on consumer responses. Clothing and Textiles Research Journal, 1997; 15(3), p. 147-154.

[15] Y Wang, "Fiber and Textile Waste Utilization," Waste Biomass Valor, 2010; 1, 135-143.

[16] P Thompson, P Willis and N Morley, "A review of commercial textile fibre recycling technologies," WRAP, 2012.

[17] S S Muthu, Y Li, J-Y Hu and P-Y Mok, "Recyclability Potential Index (RPI): The concept and quantification of RPI for textile fibres," Ecological Indicators, 2012; 18, p. 58-62.

[18] Kotiba Hamad, Mosab Kaseem, Fawaz Deri Polymer Degradation and Stability, 2013; 98, p. 2801-2812

[19] Mantia FP, Botta L, Morreale M, Scaffaro R. Effect of small amounts of poly(-lacticacid) on the recycling of poly(ethylene terephthalate) bottles. Polym Degrad Stab 2012; 97, p. 21-31.

[20] Navarro R, Ferrandiz S, Lopez J, Segui VJ. The influence of polyethylene in the mechanical recycling of polyethylene terephthalate. J Mater Proc Technol 2008; 195, 110- 122. 